\title{
Excitation of Locus Coeruleus Neurons by Vasoactive Intestinal Peptide: Role of CAMP and Protein Kinase A
}

\author{
Y.-Y. Wang and G. K. Aghajanian \\ Departments of Pharmacology and Psychiatry, School of Medicine, Yale University, and the Ribicoff Research Facilities, \\ Connecticut Mental Health Center, New Haven, Connecticut 06508
}

\begin{abstract}
In accord with previous studies, it was found that vasoactive intestinal peptide (VIP), a powerful activator of adenylate cyclase, and CAMP-active agents (i.e., 8-Br-cAMP, forskolin, and $\mathrm{Ro20}-1724$ ) increased the firing rate of noradrenergic neurons in the locus coeruleus (LC) by inducing an inward current. The response to VIP was usually more rapid and larger in a subpopulation of LC neurons with subthreshold rhythmic oscillations in membrane potential (oscillatory cells) as compared to nonoscillatory cells. In either case, the inward currents elicited by VIP and cAMP-active agents were found to be nonadditive, suggesting the action of VIP, at least in part, is via the same mechanism as that of cAMP. active agents. Intracellular application of a specific protein (or related peptide) inhibitor of CAMP-dependent protein kinase markedly attenuated the activation induced by either cAMP-active agents or VIP, suggesting that CAMP-dependent protein kinase (protein kinase A), presumably through protein phosphorylation, plays a role in the action of VIP. Taken together, the results provide evidence that CAMP and protein kinase $A$ are involved in mediating the electrophysiological actions of VIP on LC neurons.
\end{abstract}

It is well known that cAMP plays a variety of important roles as an intracellular second messenger in regulating cell function in the CNS (for review, see Drummond, 1984). In virtually all cases, the effects of cAMP are via the activation of cAMPdependent protein kinase (protein kinase $A, P K A$ ), which in turn phosphorylates its substrates to induce physiological changes (for review, see Nestler and Greengard, 1989); in some cases, the phosphorylated substrates may include ion channels (Levitan, 1985).

We have previously reported that vasoactive intestinal peptide (VIP) and cAMP-active agents increase the firing of noradrenergic neurons in the locus coeruleus (LC) by inducing an inward current. The inward current induced by VIP shares a number of similarities with that induced by several types of cAMP-active agents (i.e., 8-Br-cAMP, a membrane-permeable analog of cAMP; forskolin, an activator of adenylate cyclase; and Ro20-1724, a preferential inhibitor of cAMP-phosphodiesterase; Wang and Aghajanian, 1987, 1989a). The currents

\footnotetext{
Received Feb. 6, 1990; revised June 6, 1990; accepted June 7, 1990.

We thank Ms. Nancy Margiotta for technical assistance and Dr. Eric J. Nestler for his thoughtful suggestions about this manuscript. This work was supported by U.S. Public Health Service grant MH 25642 and by the State of Connecticut.

Correspondence should be addressed to G. K. Aghajanian, Department of Psychiatry, Connecticut Mental Health Center, 34 Park Street, New Haven, CT 06508. Copyright (C) 1990 Society for Neuroscience $0270-6474 / 90 / 103335-09 \$ 03.00 / 0$
}

elicited by either VIP or CAMP-active agents are (1) inward over the potential range of $-50 /-60$ to $-120 \mathrm{mV}$ without reversal in the region of the potassium reversal potential, (2) accompanied by a small increase in conductance, (3) resistant to TTX (a fast, voltage-dependent $\mathrm{Na}^{+}$channel blocker) or cobalt $\left(\mathrm{Co}^{2+}\right.$, a $\mathrm{Ca}^{2+}$ channel blocker), and (4) markedly reduced by decreasing extracellular $\mathrm{Na}^{+}$concentrations in the presence of normal $\mathrm{Cl}^{-}$ levels. Furthermore, in almost all the brain tissues examined in biochemical studies, including the LC (R. S. Duman and E. J. Nestler, personal communication), VIP has been documented to cause a large intracellular accumulation of cAMP (DeschodtLanckman et al., 1977; Quik et al., 1978; Borghi et al., 1979; Van Calker et al., 1980; Daly et al., 1982; Etgen and Browning, 1983; Magistretti and Schorderet, 1985; Weiss et al., 1985; Olasmaa et al., 1987; Duman et al., 1989). One of the purposes of the present study was to investigate whether the electrophysiological action of VIP in the LC is mediated by cAMP. In addition, because cAMP-dependent protein kinase has been demonstrated to exist at high levels in LC neurons (Nestler and Tallman, 1988), and because preliminary results have shown that the electrophysiological action of cAMP-active agents in LC neurons is attenuated or abolished by an inhibitor of cAMPdependent protein kinase (Wang and Aghajanian, 1989b), we investigated whether the activation elicited by VIP in LC neurons is also mediated by cAMP-dependent protein kinase, utilizing a highly specific protein inhibitor of cAMP-dependent protein kinase (PKI; Walsh et al., 1971) or a 20-residue peptide inhibitor $\left(\mathrm{PKI}_{5-24}\right)$ corresponding to the active site of $\mathrm{PKI}$ (Cheng et al., 1986).

\section{Materials and Methods}

The VIP was from Bachem or Peninsula; PKI (Lot 97F-9600; activity, $1 \mu \mathrm{g}$ protein inhibits 1 phosphorylating unit of PKA) and 8-Br-cAMP were from Sigma; $\mathrm{PKI}_{5-24}$ was from Calbiochem or Peninsula; forskolin was from Calbiochem; Ro20-1724 was kindly provided by HoffmannLa Roche, Inc.

The methods for preparation and maintenance of the LC slices were similar, except for slight modifications, to those previously described (Aghajanian and Wang, 1986). Briefly, brain taken from chloral hydrateanesthetized male albino rats (110-190 gm, Charles River) was dissected into a 3-4-mm-thick block of tissue, which was then cut into coronal slices $(\sim 300 \mu \mathrm{m})$ with a vibrating knife microtome (Vibroslice, WPI). A slice containing the LCs was incubated in a fluid-gas interface chamber with continuous perfusion of artificial cerebrospinal fluid (ACSF) at a rate of $\sim 1 \mathrm{ml} / \mathrm{min}$; the temperature in the chamber was gradually raised from room temperature to $33 \pm 0.5^{\circ} \mathrm{C}$. The ACSF $(\mathrm{pH}, 7.37-$ 7.4), equilibrated with $95 \% \mathrm{O}_{2}: 5 \% \mathrm{CO}_{2}$, was normally composed of (in $\mathrm{mM}$ ): $\mathrm{NaCl}, 126 ; \mathrm{KCl}, 5 ; \mathrm{NaH}_{2} \mathrm{PO}_{4}, 1.25$; D-glucose, $10 ; \mathrm{NaHCO}_{3}, 26$; $\mathrm{CaCl}_{2}, 2 ; \mathrm{MgSO}_{4}, 2$. ACSF with equimolar (calculated) replacement of $50 \% \mathrm{NaCl}$ by sucrose (ACSF-sucrose, $126 \mathrm{~mm}$ sucrose, $63 \mathrm{~mm} \mathrm{NaCl}$ ) was used during dissection and the first $\mathrm{hr}$ of perfusion in the slice 

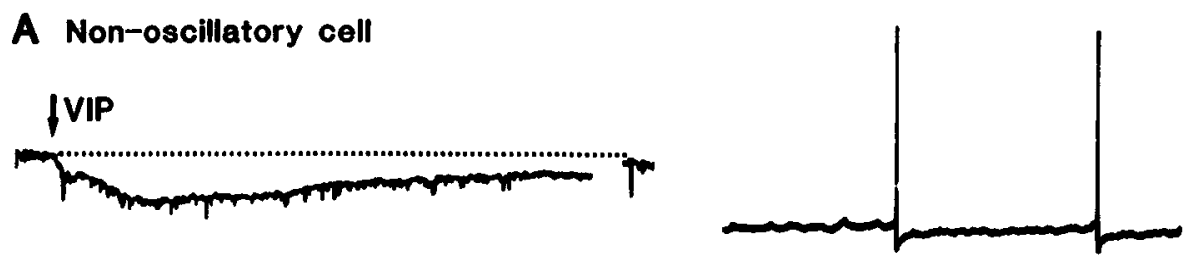

\section{B Oscillatory cell}
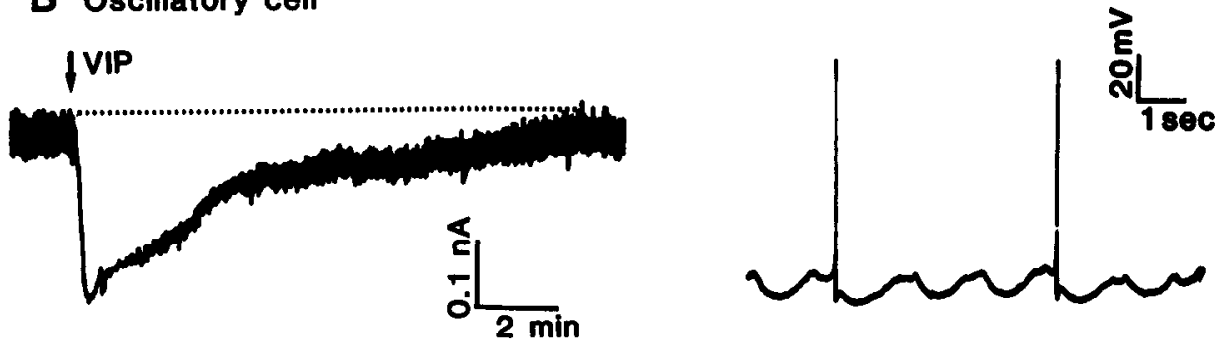

Figure 1. Comparison of VIP-induced inward currents and subthreshold membrane potentials in nonoscillatory and oscillatory LC cells. $A$, Nonoscillatory cells. The left trace shows the inward current at $-60 \mathrm{mV}$ elicited by puff application of VIP under voltage clamp (the small gap on the trace was due to switching away from voltage-clamp mode to check DC level); right trace shows a slow oscilloscope sweep (10 sec) of subthreshold membrane potential intracellularly recorded under current clamp. In the left trace of $A$, note the relatively low amplitude and slow onset of the inward current in response to VIP; in the right trace, note the virtual absence of subthreshold membrane oscillations. $B$, Oscillatory cells. The left trace shows the inward current elicited by VIP; the right trace shows subthreshold membrane potential intracellularly recorded under current clamp. Note in $B$, right trace, that the large fluctuations in membrane potential (with a periodicity of approximately $1.5 \mathrm{sec}$ ) are not dependent on the occurrence of spikes (i.e., they are subthreshold). In both $A$ and $B$, right traces, a $-0.07-n A$ current was injected to reduce the occurrence of spikes for the purpose of illustrating the patterns of subthreshold membrane potential.

chamber. (The composition of ACSF-sucrose is the same as that of normal ACSF except for the partial substitution of sucrose for $\mathrm{NaCl}$.) In general, the use of sucrose has proved to be helpful in improving the survival and quality of cells, presumably by preventing neuronal swelling due to a large flux of $\mathrm{Cl}^{-}$caused by depolarization secondary to anoxia during the dissection and recovery process (Aghajanian and Rasmussen, 1989). By reflected light, the LCs were visually identified in the anterior pons as dark oval areas near the lateral borders of the central gray and fourth ventricle at a frontal plane just anterior to the genu of nerve VII.

Intracellular recording and single-electrode voltage-clamp (SEVC) experiments were conducted using an Axoclamp-2 (Axon Inst.) as previously described (Aghajanian and Wang, 1986; Wang and Aghajanian, 1987). Relatively stubby electrodes were pulled with a Model 80 Brown Flaming Micropipette Puller using Microstar tubing (Radnoti Glass Technology) or Kwik-Fil glass (WPI) and filled with $2 \mathrm{M} \mathrm{KCl}$. In some experiments as noted in the text, electrodes were filled with either PKI or $\mathrm{PKI}_{5-24}$ dissolved in $\mathrm{KCl}$. The electrode tips were usually broken to reduce the resistance to facilitate the entry of PKI and PKI ${ }_{3-24}$. Only neurons that fulfilled the following criteria were used for the intracellular recordings: high-input resistance (50-150 M $)$, large afterhyperpolarizations, long-duration action potentials ( $\sim 2 \mathrm{msec})$, spike amplitudes above $75 \mathrm{mV}$, and spontaneous firing rates under 4 spikes/sec.

VIP, dissolved in ACSF (400 or $500 \mu \mathrm{M}$ ), was applied in "puffs" at 10-20 psi lasting 0.8-1.5 sec using a pressure ejector (Pneumatic Picopump, WPI). Ejection pipettes had tips of about 15-25 $\mu \mathrm{m}$ and were positioned at the liquid interface $\sim 300 \mu \mathrm{m}$ away from the impaled cells. The cAMP-active agents were administered in the perfusate.

PKI $\left(40-150 \mathrm{mg} / \mathrm{ml}\right.$ in $2 \mathrm{M} \mathrm{KCl}$, usually $100-150 \mathrm{mg} / \mathrm{ml}$ ) or PKI $\mathrm{PK}_{5-24}$ $(1-5 \mathrm{mg} / \mathrm{ml}$ in $1 \mathrm{M} \mathrm{KCl})$ was filled into electrodes $(10-30 \mathrm{M} \Omega$ with PKI, $2 \mathrm{M} \mathrm{KCl}$; or $20-60 \mathrm{M} \Omega$ with $\mathrm{PKI}_{5-24}, 1 \mathrm{M} \mathrm{KCl}$ ). The apparent resistance of electrodes containing high concentrations of protein or peptide was higher than similar electrodes containing only $2 \mathrm{M} \mathrm{KCl}$. To facilitate the extrusion of the inhibitor, PKI was ejected into neurons by passing negative current $(0.6-2.0 \mathrm{nA})$ for a cumulative time of 15-25 min. $\mathrm{PKI}_{5-24}$ was ejected into neurons by passing pulses of positive current (0.6-0.8 nA, 600-msec duration, 1-sec interval) for a net time of 1215 min. Denatured PKI solution was made from boiled PKI solution $100 \mathrm{mg} / \mathrm{ml}$ in $2 \mathrm{M} \mathrm{KCl}$, heated for $\sim 15 \mathrm{~min}$ at $100^{\circ} \mathrm{C}$ ).

In additivity experiments, peak inward current measured by SEVC was used as an index of response. The concentration of 8-Br-cAMP (2 $\mathrm{mm}$ ) was chosen to achieve a near maximal response. At the concentration of $5 \mu \mathrm{M}$, forskolin produced an effect comparable to that of
8-Br-cAMP without discernible side effects (Wang and Aghajanian, 1987) The concentration of Ro20-1724 was $100 \mu \mathrm{M}$, which is near its maximal solubility in water. VIP at concentrations of 400-500 $\mu \mathrm{M}$ and the given parameters induced a near maximal response. Prolonged SEVC had several disadvantages (e.g., a tendency for cell deterioration and artifactual DC shifts). Therefore, in protein kinase blockade experiments, firing rate rather than current was chosen as the response index because the experiments required long-term recordings (due to the time required for the ejection of $\mathrm{PKI}$ and $\mathrm{PKI}_{5-24}$ and the need for retesting following recovery from the effects of cAMP-active agents or VIP). Furthermore, the holding current under SEVC per se would have an effect on the ejection of PKI (negatively charged) or $\mathrm{PKI}_{5-24}$ (positively charged) into cells. To shorten recovery time, the concentration of 8-Br-cAMP was reduced to $1 \mathrm{~mm}$ in most of protein kinase blockade experiments to allow for repeated applications of 8-Br-cAMP or testing of 8-Br-cAMP and VIP on the same cells. Under our experimental conditions, the recovery time for $8-\mathrm{Br}$-cAMP at $1 \mathrm{mM}(10 \mathrm{~min}$ perfusion) was about $25-50 \mathrm{~min}$, whereas at $2 \mathrm{mM}(\sim 20 \mathrm{~min}$ perfusion), recovery time was $>1.5 \mathrm{hr}$. Data were expressed as mean $\pm \mathrm{SE}$. Student's $t$-test was performed to determine significant difference between means.

\section{Results}

As prcviously notcd (Wang and Aghajanian, 1987, 1989a), in about $1 / 3$ of the LC cells, membrane potential exhibited a subthreshold rhythmic oscillation with a regular interval and an amplitude of about 5-16 mV (Fig. 1B). Cells whose membrane potential exhibited an oscillation above $5 \mathrm{mV}$ were categorized as oscillatory cells, while the cells whose membrane potential exhibited no or slight oscillation (i.e., $<5 \mathrm{mV}$ ) were categorized as nonoscillatory cells. Among 75 cells analyzed, the occurrence of nonoscillatory and oscillatory cells was 48 $(64 \%)$ and $27(36 \%)$, respectively. In nonoscillatory cells, the peak response (inward current or increase in firing rate) to VIP was relatively small: the inward current elicited by VIP at -60 $\mathrm{mV}$ was $0.086 \pm 0.004 \mathrm{nA}$ (mean $\pm \mathrm{SE}, n=48$ ), which is in the range of inward current induced by cAMP-active agents (Wang and Aghajanian, 1987; see below). In addition, the time required for reaching peak response to VIP was relatively long, 


\section{A a non-oscillatory cell}

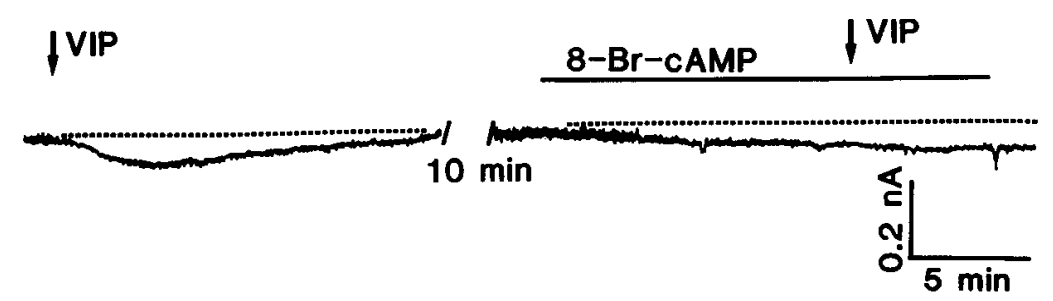

B an oscillatory cell

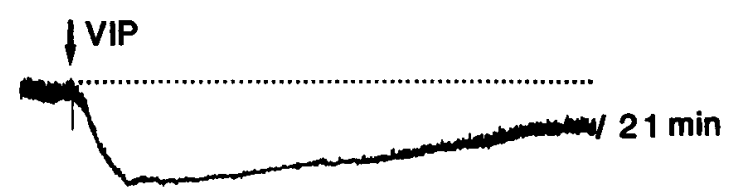

8-Br-CAMP IVIP

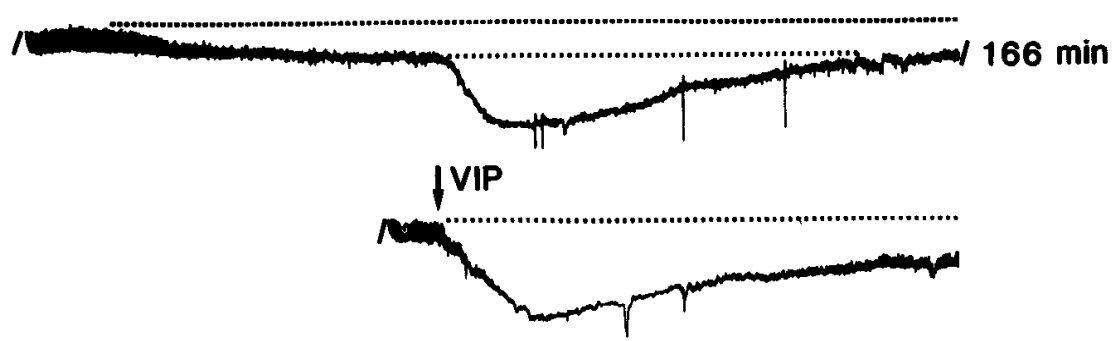

Figure 2. Nonadditivity of the inward currents induced by $8-\mathrm{Br}-\mathrm{cAMP}$ and VIP. The inward current at $-60 \mathrm{mV}$ was measured under SEVC. $A$, In a nonoscillatory cell, VIP was tested prior to the administration of $8-\mathrm{Br}$-cAMP, then after the effect of 8-Br-cAMP approached a maximum. $B$, In an oscillatory cell, as indicated by the thickness of the current trace, VIP was administered in the absence and presence and after the washout of $8-\mathrm{Br}$-cAMP. The traces in $B$ are from continuous recording in the same cell: the first gap in the current trace represents $21 \mathrm{~min}$; the second gap represents $166 \mathrm{~min}$. VIP $(400$ $500 \mu \mathrm{M}$ ) was applied by pressure ejection at the time points indicated by the arrows. The ranges of pressure and time for application of VIP by a pressure ejector were $10-20 \mathrm{psi}$ and $0.8-1.5 \mathrm{sec}$ respectively. These values were selected so as to give a near maximal response to VIP. 8-Br-cAMP (2 mM) was administered in the perfusate. Time and current scales apply to all the traces. taking about 3-5 $\mathrm{min}$ (Fig. $1 A$ ). In oscillatory cells, the inward current (or under current clamp, the increase in firing rate) induced by VIP was relatively large: the current elicited by VIP at $-60 \mathrm{mV}$ was $0.203 \pm 0.014 \mathrm{nA}(n=27)$. In addition, the time for reaching peak response was relatively short, taking about $0.5-2 \mathrm{~min}$. Moreover, recovery often exhibited a rapid initial decrement, then a slower recovery phase (Fig. $1 B$ ). It is of interest that the oscillation was not eliminated under voltage clamp, accounting for the greater "noise" in current traces from oscillatory cells. It is also of interest that the amplitude of oscillation was markedly diminished during the peak response to VIP (Figs. $1 B, 2 B, 4$ ), 8-Br-cAMP (Fig. 2B), or Ro20-1724 (Fig. 4). Although there were several differences in the response to VIP between nonoscillatory and oscillatory cells, the average recovery time for both was similar: $13.1 \pm 1.1 \mathrm{~min}$ and 13.2 $\pm 1.5 \mathrm{~min}$ for the former and the latter, respectively (Fig. 1). The apparent input resistance was usually higher $(>100 \mathrm{M} \Omega)$ in nonoscillatory cells than in oscillatory cells (50-80 M $)$. It should be pointed out that, in a small percentage of cells, the differences in response to VIP between nonoscillatory and oscillatory cells were not always clearly evident.

The response to VIP was evaluated in the absence and presence of cAMP-active agents (i.e., 8-Br-cAMP, forskolin, and Ro20-1724), based on the notion that, if the action of VIP is through an increase in the intracellular levels of cAMP, the effect of VIP should be nonadditive with that of CAMP-active agents. Because the degree to which the effect of VIP was preempted (or occluded) by cAMP-active agents usually depended on whether cells were nonoscillatory or oscillatory, the data from nonoscillatory or oscillatory cells were analyzed separately. In nonoscillatory cells (Figs. $2 A, 3 A$ ), the first application of VIP (in the absence of cAMP-active agents) induced a relatively small inward current at $-60 \mathrm{mV}$. After recovery from the first application of VIP, 8-Br-cAMP or forskolin, administered for 13-16 min (the time required for their effect to approach maximum), produced an inward current similar in amplitude to that induced by VIP alone. A second application of VIP superimposed on the effect of cAMP-active agents induced little further current. In oscillatory cells (Figs. $2 B, 3 B$ ), VIP applied alone produced a relatively large peak inward current at $-60 \mathrm{mV}$. Following recovery from VIP, 8-Br-cAMP or Ro20-1724 administered for 13-16 min produced an inward current of similar magnitude to that induced in nonoscillatory cells. In contrast to the almost complete occlusion of VIP effects by cAMP-active agents in nonoscillatory cells, superimposed application of VIP generated additional inward current in the oscillatory cells. Although the effect of VIP in oscillatory cells was only partially occluded by cAMP-active agents, the total average peak current generated by cAMP-active agents plus VIP was not significantly different from that elicited by VIP alone, indicating the effects of VIP and cAMP-active agents were still nonadditive. The response to VIP returned to its original level after recovery from cAMP-active agents (e.g., Fig. $2 B$ ). It should be noted that, when distinct fast and slow components of the response to VIP could be discriminated in oscillatory cells, the cAMP-active agents appeared to preferentially suppress the slow component, thereby accelerating overall recovery. As illustrated in Figure 4, time for recovery from the overall response to VIP was reduced in the presence of Ro20-1724. Among the cells analyzed, the time for half recovery from the total response in the presence of either 


\section{A non-oscillatory cells}

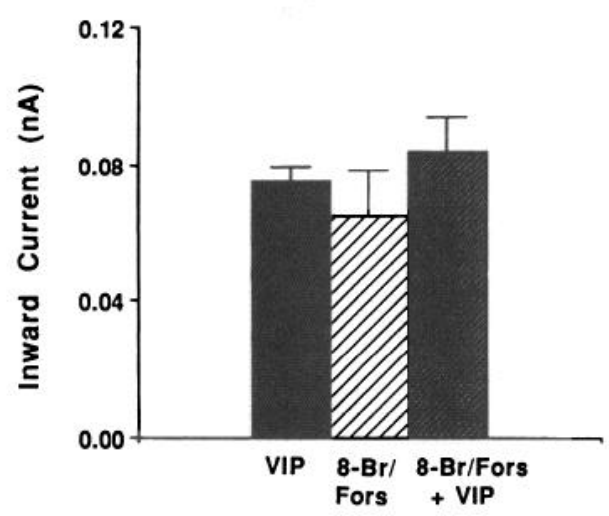

B oscillatory cells

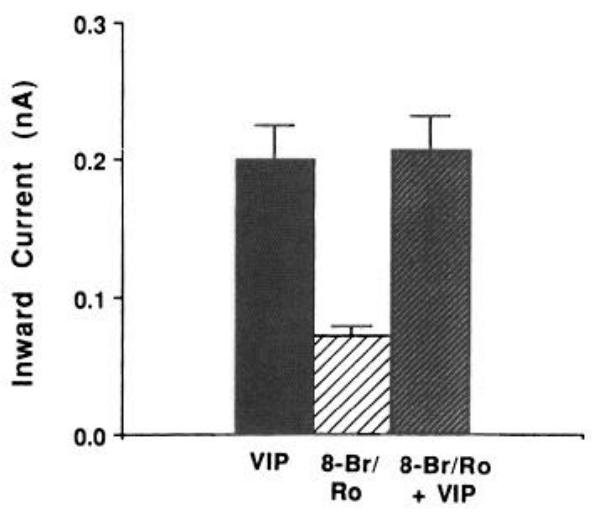

Figure 3. Summarized results showing that peak inward currents evoked by VIP and cAMP-active agents were nonadditive. $A$, Data from 8 nonoscillatory cells. When VIP was given alone, it produced an average peak inward current of $0.075 \mathrm{nA}$. Following recovery, 8-Br-cAMP (8$B r ; 2 \mathrm{mM}, n=7$ ) or forskolin (Fors; $5 \mu \mathrm{M}, n=1$ ), applied for 13-16 min, produced a mean inward current of $0.065 \mathrm{nA}$, which is not significantly different from the current produced by VIP alone $(p>0.43$, Students $t$-test). Superimposed application of VIP did not produce a significant further effect. The total average inward current elicited by 8-Br-cAMP or forskolin plus VIP was $0.084 \mathrm{nA}$, which is not significantly different from that elicited by VIP alone $(p>0.33) . B$, Data were from 5 oscillatory cells. The total average peak current elicited by 8-Br-cAMP (8-Br; $2 \mathrm{mM}, n=3)$ or Ro20-1724 $(R o ; 100 \mu \mathrm{M}, n=2)$ plus VIP was $0.208 \mathrm{nA}$, which is not significantly different from that elicited by VIP alone $(0.20 \mathrm{nA} ; p>0.24)$. Note the difference in scale for Inward Current between $A$ and $B$. Data are mean $\pm \mathrm{SE}$, as described in Materials and Methods.

8-Br-cAMP $(n=2)$ or Ro20-1724 $(n=2)$ was $5.1 \pm 2.7 \mathrm{~min}$, a significant reduction $(p<0.05$, Student's $t$-test) compared with controls $(8.1 \pm 3.3 \mathrm{~min})$.

To investigate whether PKA may be involved in the action of VIP, highly specific inhibitors of PKA (PKI or $\mathrm{PKI}_{5-24}$, a synthetic peptide corresponding to the active site of native protein inhibitor) were utilized. We first examined whether the PKI or $\mathrm{PKI}_{5-24}$ could block the effect of cAMP-active agents in order to establish that PKA, presumably through protein phosphorylation, was essential for the actions of cAMP in LC neurons. In agreement with previous results (Wang and Aghajanian, 1987), perfusion with 8 -Br-cAMP (1 mM) or forskolin $(5 \mu \mathrm{M})$ for $10-$ $12 \mathrm{~min}$ reversibly and reproducibly increased the firing rate of LC neurons by $1.5-2$-fold when control electrodes $(2 \mathrm{M} \mathrm{KCl})$ were employed (Figs. 5A,C;6A). In contrast, when PKI or $\mathrm{PKI}_{5-24}$ was intracellularly ejected prior to each application, the increase in firing induced by 8 -Br-cAMP or forskolin was either substantially attenuated or completely blocked (Figs. $5 B, D ; 6 B$ ). In some cells, the first application of the cAMP-active agents in the presence of PKI or $\mathrm{PKI}_{5-24}$ still activated LC neurons, though to a lesser extent than in controls. However, the recovery from activation $(11.7 \pm 1.8 \mathrm{~min})$ was approximately 2.5 times faster than controls $(40.2 \pm 5.8 \mathrm{~min})$. Moreover, some cells slowed down below original baseline (Figs. $5 D, 6 B$ ) or suddenly hyperpolarized (not shown) soon after turning off the cAMPactive agents. After waiting the normal recovery time, the second application of the above agents produced much less or no activation, or in the case of forskolin, a slight suppression was sometimes observed (Fig. $6 \mathrm{~B}$ ). The above results are summarized in Figure 7. The activation by Ro20-1724 (100 $\mu \mathrm{M})$ was also blocked by PKI to a similar degree as that by forskolin. In controls, Ro20-1724 increased the firing rate of LC neurons by $140.5 \pm 30.7 \%(n=7)$, whereas in the presence of intracellular PKI, the mean increase in the firing rate by Ro20-1724 was $23.7 \pm 21.5 \%(n=3), \mathrm{a} \sim 80 \%$ reduction $(p<0.05)$. In addition, as observed with forskolin, the second application of Ro20-1724 evoked either no activation or a slight suppression $(-22.2 \pm$ $22.2 \%, n=2$ ). Denatured PKI solution was ineffective in blocking the effect of 8 -Br-cAMP $(n=3)$. Moreover, because the relatively pure synthetic peptide inhibitor $\left(\mathrm{PKI}_{5-24}\right)$ was as effective as the native protein inhibitor (PKI), it also served as a control for the specificity of action of PKI.

Because the effect of cAMP-active agents was reduced or abolished by $\mathrm{PKI}$ or $\mathrm{PKI}_{5-24}$, it was of interest to determine whether PKI or $\mathrm{PKI}_{5-24}$ would block the activation of $\mathrm{LC}$ neurons by VIP. Under control conditions, VIP induced a reproducible increase in the firing of LC cells (Fig. $8 A$ ). Following intracellular iontophoresis of $\mathrm{PKI}_{5-24}$, the increase in the firing rate elicited by a second application of VIP was significantly smaller than that in controls (Fig. $8 \mathrm{~B}$ ). These results are summarized in Figure $9 \mathrm{~A}$. In response to the ejection of $\mathrm{PKI}_{5-24}$ alone, $\sim 70 \%$ of cells showed a deceleration in firing rate or a slight hyperpolarization to just below resting membrane potential $(-60 \mathrm{mV}$; e.g., see Fig. $8 B$, legend); in such cases, a small constant positive current was given for the purpose of restoring baseline firing rate. The ejection of either positive or negative current per se did not alter the response to VIP or cAMP-active agents in controls. In an additional 5 cells, the effects of VIP or 8-Br-cAMP were compared in the same cells in the presence of PKI. The activation by both 8 -Br-cAMP and VIP was significantly reduced compared with controls (Fig. $9 B$ ). It should be noted that PKI or $\mathrm{PKI}_{5-24}$ also accelerated recovery from VIP (Fig. $8 B$ ), as it did in the case of the cAMP-active agents (Figs. 4, 6B).

\section{Discussion}

In the first part of this study, it was found that the inward currents induced by VIP and cAMP-active agents are not additive, suggesting that the actions of VIP may involve cAMP as a second messenger. In the second part of this study, it was found that the activation of LC neurons by VIP or cAMP-active agents is markedly attenuated by highly specific inhibitor of PKA (PKI or $\mathrm{PKI}_{5-24}$ ), suggesting that PKA, presumably through protein phosphorylation, plays a role in the actions of VIP, reinforcing the idea that cAMP may mediate the effects of VIP. Moreover, the similarities in the inward currents elicited by VIP and cAMP-active agents previously reported (Wang and Agha- 


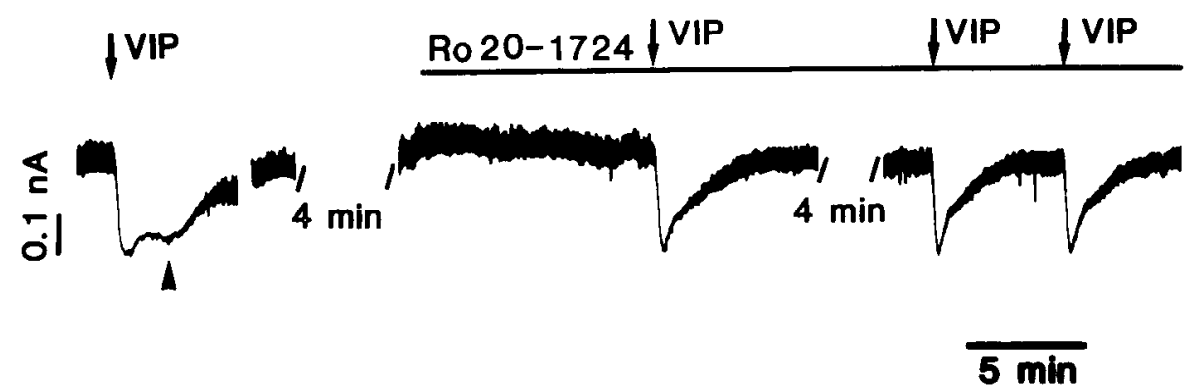

Figure 4. Ro20-1724 altered time course for recovery from VIP-activation in oscillatory cells (indicated by thickness of current trace). Cell membrane was clamped at $-60 \mathrm{mV}$. The VIP-induced inward current was measured with or without Ro20-1724 (100 $\mu \mathrm{M}$ ). Ro20-1724 reduced the $1 / 2$ recovery time from VIP activation, due to the elimination of the second small peak response, indicated by the arrowhead. The small gap during the first segment trace was due to switching away from voltage-clamp mode to check DC level.

janian, 1987, 1989a) are consistent with the view that cAMP is involved in VIP signal transduction in LC neurons. Furthermore, in a biochemical study, VIP has been demonstrated to be a potent activator of adenylate cyclase in the LC (R.S. Duman and E. J. Nestler, unpublished observations), as it is elsewhere in the CNS (see references in Introduction). Although this biochemical effect of VIP is not necessarily causally related to the electrophysiological actions of VIP, the slow rate of onset, the delay in reaching peak response, and the prolonged action of VIP with a single puff application are suggestive of the idea that a second messenger such as CAMP may be involved in the actions of VIP (see also Wang and Aghajanian, 1989a).

A consistent observation, with both $\mathrm{PKJ}$ and $\mathrm{PKI}_{5-24}$, was that the degree of blockade of VIP in terms of both amplitude and duration of its effect progressed from the first application to the second. A possible explanation for this phenomenon lies in the mechanism of action of PKI. The PKI inhibits catalytic activity of PKA by interacting specifically with free catalytic subunits dissociated from the holoenzyme in response to the stimulation of cAMP (Ashby and Walsh, 1972, 1973). Thereforc, the blocking effect of PKI depends on the availability of free catalytic subunits of PKA. Before the application of cAMP-active agents or VIP, the main form of PKA would be the holoenzyme, while after application of cAMP-active agents or VIP, free catalytic subunits are released from the holoenzyme, and binding of PKI to the free catalytic subunits can then cause inhibition of activation induced by cAMP-active agents or VIP. Additionally, it is likely that more PKI would have entered cells with prolonged periods of ejection and recording. Based on the occlusion experiments with the cAMP-active agents, one would expect that, in oscillatory cells, PKI would preferentially suppress the slow phase of the VIP response. However, in the presence of PKI (or

\section{A Control}

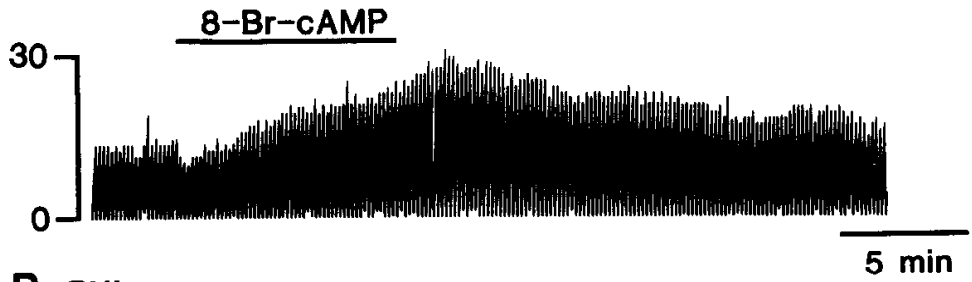

B PKI
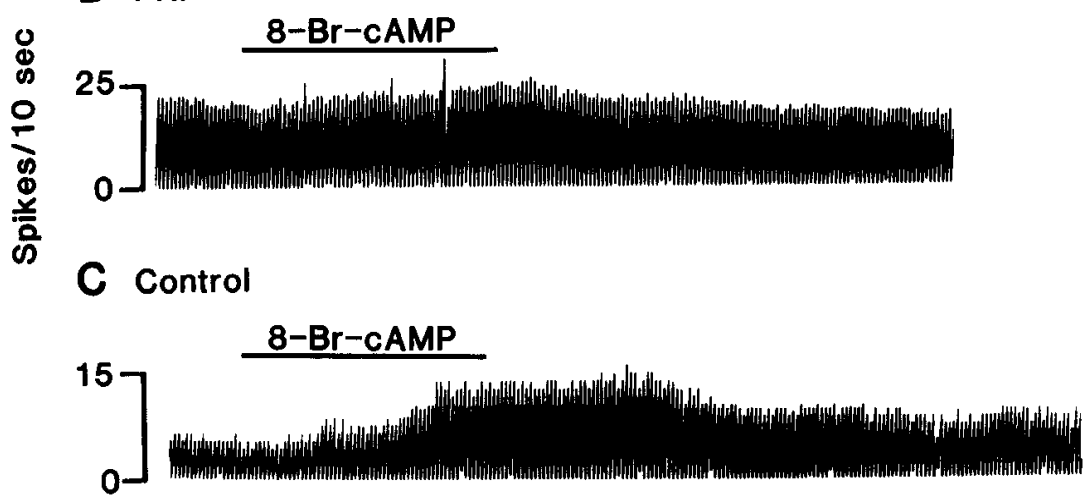

D $\mathrm{PKI}_{5-24}$

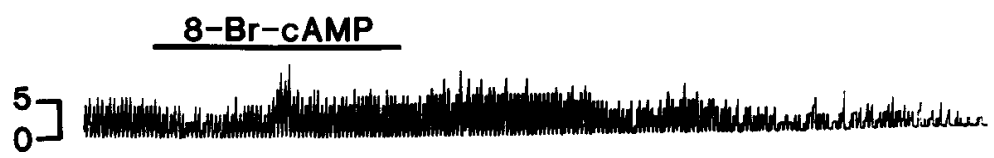

Figure 5. Intracellular administration of protein kinase inhibitor (PKI or $\mathrm{PKI}_{5-24}$ ) blocked increase in firing rate induced by 8 -Br-cAMP ( $1 \mathrm{mM})$ in LC neurons. Each vertical line represents the integrated firing rate, counted as spikes per $10 \mathrm{sec}$ and displayed on a chart recorder. The time scale applies to all traces. $A$ and $C, 8$-Br-cAMP increased the firing in LC neurons with control electrodes $(2 \mathrm{M} \mathrm{KCl}) . B$ and $D$, PKI $(100 \mathrm{mg} / \mathrm{ml})$ or PKI $_{5-24}(1 \mathrm{mg} / \mathrm{ml})$ was ejected into cells by iontophoresis from electrodes preceding the application of 8-Br-cAMP. The activation of 8-Br-cAMP was blocked by PKI or $\mathrm{PKI}_{5-24}$. In both $B$ and $D$, the firing of cells slowed down below the original basal firing rate, suggesting that PKI or $\mathrm{PKI}_{5-24}$ may also suppress the spontaneous activity of LC cells. The 2 controls were presented for comparable basal firing rates for $B$ and $D$, respectively. 


\section{A Control}

Figure 6. PKI blocked increase in firing induced by forskolin $(5 \mu \mathrm{M})$ in $\mathrm{LC}$ neuron. $A$, In the control, forskolin increased the firing rate by $225 \%$, and a period of $52 \mathrm{~min}$ was allowed for recovery; the second application of forskolin in the same cell produced a similar degree of activation to that of the first application. $B$, PKI $(100 \mathrm{mg} / \mathrm{ml}$ in electrode) was ejected into the cell prior to each application. Forskolin still produced some activation at the first application. However, only $15 \mathrm{~min}$ were required for recovery from the activation, and the firing of the cell became slower than that of the original baseline. The second application of forskolin in the same cell not only failed to induce any activation, but seemed to produce a slight suppression.

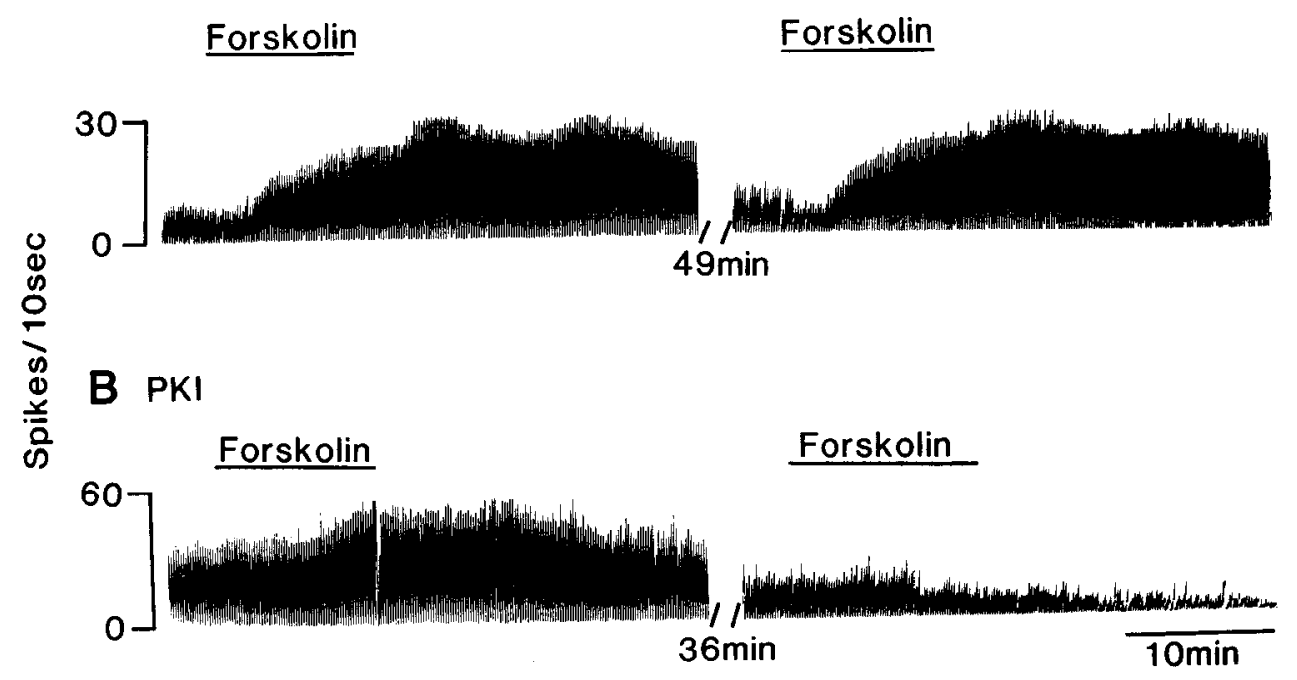

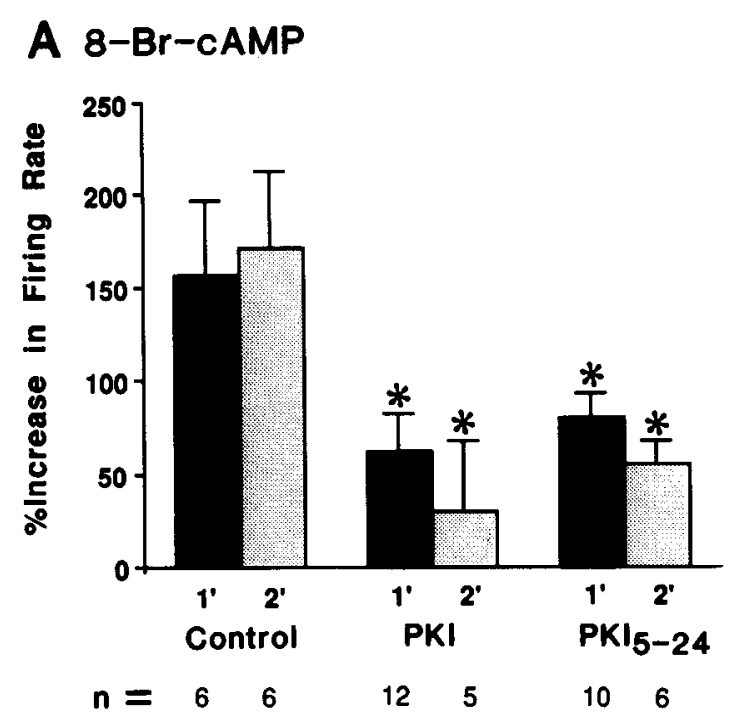

B Forskolin

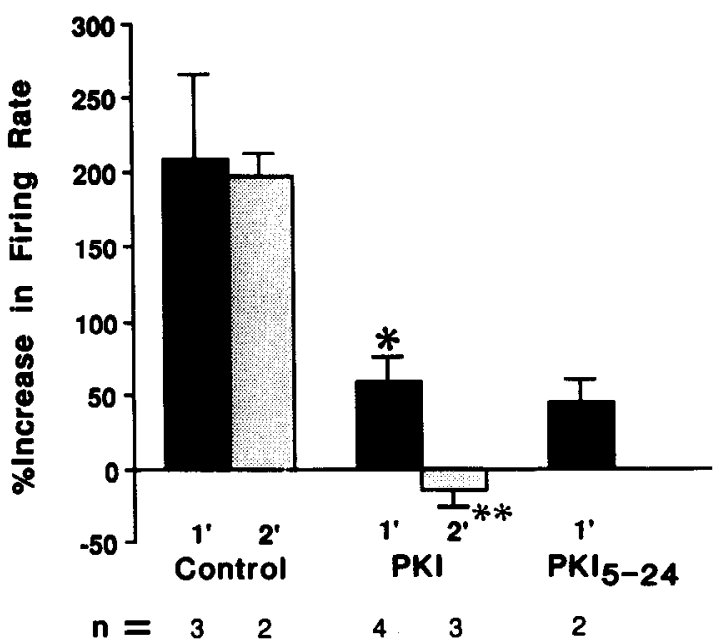

$\mathrm{PKI}_{5-24}$ ), oscillation was observed only infrequently. Therefore, we could not separately evaluate the data from oscillatory and nonoscillatory cells in the PKI experiments (see Figs. 8, 9, legends).

In peripheral neurons of the mouse dorsal root ganglion (Chen et al., 1988) and certain invertebrate neurons (Adams and Levitan, 1982; Castellucci et al., 1982; Onozuka et al., 1988; Conn et al., 1989), the electrophysiological effects of cAMP-active agents or certain neurotransmitters (e.g., opioid peptides and serotonin) have been demonstrated to be blocked by the same specific inhibitor of cAMP-dependent protein kinase (PKA) as was employed in the present study. To our knowledge, the present study is the first demonstration that the intracellular ejection of this specific inhibitor of PKA can inhibit the electrophysiological actions of cAMP-active agents and a neurotransmitter (VIP) in a mammalian central neuron. Our success in blocking cAMP-mediated responses with intracellular applications of PKI or $\mathrm{PKI}_{5-24}$ suggests this approach may be applied to other situations where synaptic responses in mammalian central neurons are mediated by cAMP (e.g., the $\beta$-receptor-mediated suppression of slow afterhyperpolarizations in rat hippocampal CA1 pyramidal neurons; Madison and Nicoll, 1986; Nicoll, 1988).

The subthreshold rhythmic oscillation of membrane potential in LC neurons has been noted in our previous papers (Wang and Aghajanian, 1987, 1989a) and reported extensively else-

Figure 7. Summarized results showing blockade of 8-Br-cAMP (1 mM) or forskolin $(5 \mu \mathrm{M})$ by PKI or PKI ${ }_{5-24} .8-\operatorname{Br}$-cAMP $(A)$ or forskolin $(B)$ was tested twice in the same cells in each condition. Control, electrodes containing 1 or $2 \mathrm{M} \mathrm{KCl}$ or denatured PKI in $2 \mathrm{M} \mathrm{KCl}$ were used; PKI, electrodes containing PKI $(40-150 \mathrm{mg} / \mathrm{ml}$ in $2 \mathrm{M} \mathrm{KCl}$, mostly $100-150$ $\mathrm{mg} / \mathrm{ml})$ were used; $\mathrm{PKI}_{5-24}$ electrodes containing $\mathrm{PKI}_{5-24}(1 \mathrm{mg} / \mathrm{ml}$ in 1 $\mathrm{M} \mathrm{KCl}$ ) were used. PKI or $\mathrm{PKI}_{5-24}$ was iontophoretically ejected into the cell prior to each application of $8-\mathrm{Br}$-cAMP or forskolin. $1^{\prime}$ represents the first application; 2' represents the second application (the second application was given after recovery from the first application). The number of cells $(n)$ is reduced for the repeat applications because prolonged recordings could not be obtained in all cases. *, significantly different from control, $p<0.05 ; * *$, significantly different from control, $p<0.002$. 


\section{A Control}

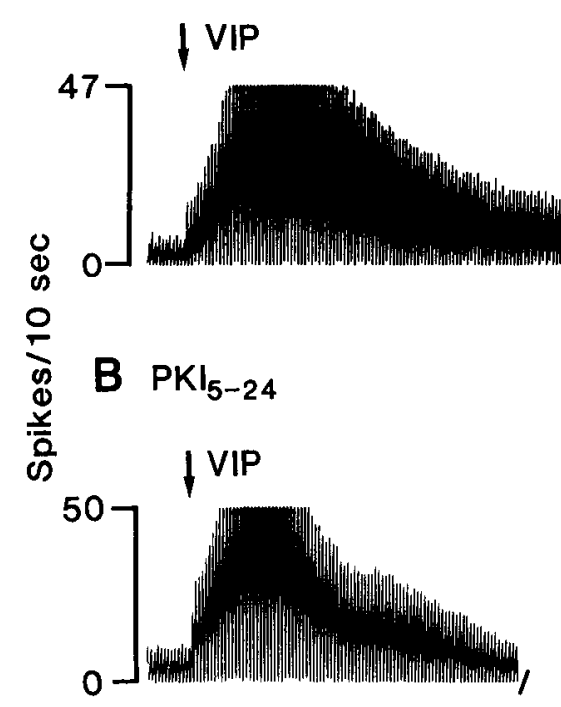

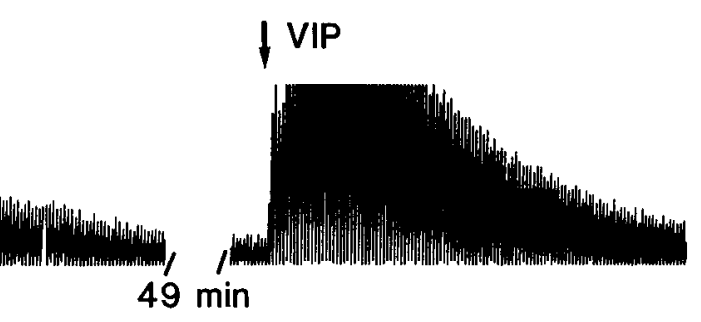

| VIP

$30 \mathrm{~min}$

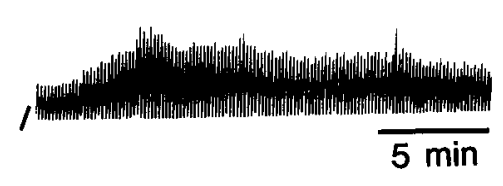

Figure 8. $\mathrm{PKI}_{5-24}$ attenuated the increase in firing induced by VIP. Vertical lines represent the integrated firing rate. VIP was applied by pressure ejection at the time points indicated by arrows. $A$, In a control, VIP caused reproducible activation in the same cell. Because this cell was slightly hyperpolarized at beginning, a small constant positive current $(0.05 \mathrm{nA})$ was injected to maintain a basal firing rate. $B, \mathrm{PKI}_{5-24}(5 \mathrm{mg} / \mathrm{ml}$ in electrode) was iontophoretically ejected into the cell prior to the second application of VIP. Because the cell was slightly hyperpolarized after this ejection, a small constant positive current $(0.05 \mathrm{nA})$ was injected to maintain a similar basal firing rate as before. The activation induced by VIP at the second application was markedly attenuated in the same cell. Note that, in $B$, the response to VIP at the first application may not be the reflection of 2 phases, but rather that the recovery of VIP was accelerated in the presence of $\mathrm{PKI}_{5-24}$ (sec Discussion for the mechanism action of PKI). where (Williams and Marshall, 1987; Christie et al., 1989). There is general agreement that the oscillations occur more frequently in LC cells from younger than from older rats, and that apparent input resistance is usually lower in the oscillatory cells than in the nonoscillatory cells. However, we still observed substantial oscillation in about $1 / 3$ of cells from the 33-37-d-old rats, while in the other studies (Williams and Marshall, 1987; Christie et al., 1989) oscillatory cells were rarely observed in slices from rats older than $27 \mathrm{~d}$. These differences may be due to variations in experimental procedure or in the strains of rats used. We have previously shown that the oscillation may also depend on $\mathrm{Na}^{+}$, because a $60-80 \%$ reduction in external concentration of this ion eliminated the oscillation (Fig. 5 in Wang and Aghajanian, 1987, Fig. 4 in Wang and Aghajanian, 1989a). Christie and coworkers (1989) have proposed that the rhythmic oscillation may be due to electrotonic coupling between LC cells. The lower input resistance of oscillatory cells that we found in the present study is consistent with this possibility. It has yet to be determined whether the presence of electrotonic coupling among LC cells might have an influence on the amplitude of the response to VIP. The oscillations also occurred in membrane current when the cells were voltage clamped at subthreshold potentials; this may result either from a poor spatial clamp or, more interestingly, from a voltage-independent process. We cannot distinguish between these possibilities at the present time. In any event, both cAMP-active agents and VIP seemed to reduce the amplitude of oscillation. It is possible that the effects of these substances on oscillation may be independent of their effects on net membrane current. This issue deserves further investigation.

The response to VIP tended to exhibit 2 different patterns, depending on whether cells were nonoscillatory or oscillatory. In nonoscillatory cells, the response to VIP appeared to show mainly 1 slow phase that was almost completely preempted or occluded by cAMP-active agents. In oscillatory cells, the response to VIP often exhibited 2 phases: a high-amplitude fast component that was not mimicked by cAMP-active agents and a slow component that was occluded by cAMP-active agents. Although the reason for this difference is presently unknown, it is possible that the early current (or fast component) elicited by VIP might be regulated directly by a guanine nucleotide-binding regulatory protein ( $\mathrm{G}$ protein), and the late phase (or slow component) may be regulated indirectly by cAMP-dependent protein phosphorylation, akin to the biphasic responses mediated by $\beta$-adrenergic receptors in cardiac cells (Schubert et al., 1989; Yatani and Brown, 1989). In the guinea pig cardiac myocyte (Yatani and Brown, 1989), it has been shown that the $\beta$-adrenergic agonist isoproterenol generates a biphasic (fast and slow) increase in $\mathrm{Ca}^{2+}$ currents, whereas the cAMP-active agents induce only a slow response. It has been proposed that $\beta$-adrenergic receptors are coupled to stimulatory guanosine triphosphate-binding proteins $\left(\mathrm{G}_{\mathrm{s}}\right)$, which open $\mathrm{Ca}^{2+}$ channels not only indirectly via CAMP to produce the slow response, but also directly to produce the fast response. The direct coupling of $G$ proteins to channels has been also reported in other preparations (Pfaffinger et al., 1985; Mattera et al., 1989). The mediation of the electrophysiological actions of VIP by a G protein (possibly $\mathrm{G}_{\mathrm{s}}$ ) in LC neurons was demonstrated in a previous study (Wang and Aghajanian, 1989a). Further experiments are required to determine whether the G proteins linked to VIP receptors can directly regulate the VIP-induced inward current. An alternative explanation for the occurrence of both slow and fast components in response to VIP in oscillatory cells would be that multiple second-messenger systems with different time constants are linked to VIP receptors via G proteins. In addition to the activation of adenylate cyclase, VIP has been reported to stimulate the hydrolysis of phosphoinositides (PI) in the adrenal gland (Malhotra et al., 1988). If stimulation of PI turnover also occurs in the LC, this would represent a cAMP-independent pathway for differential actions of VIP. It is also possible that there may be different subtypes of VIP receptors.

LC neurons account for almost $1 / 2$ the noradrenergic neurons in the rat brain (Nygren and Olson, 1977), and efferents from the LC project throughout the CNS (for review; see Foote et al., 


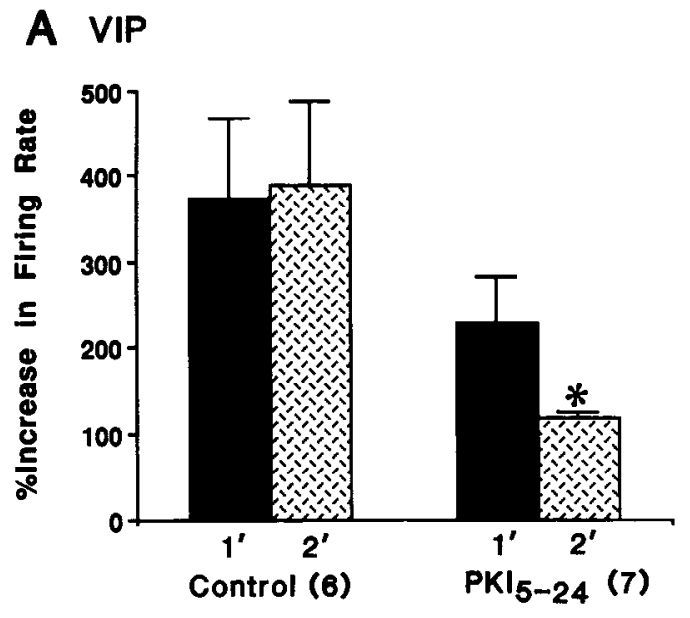

\section{B 8-Br-cAMP vs VIP}

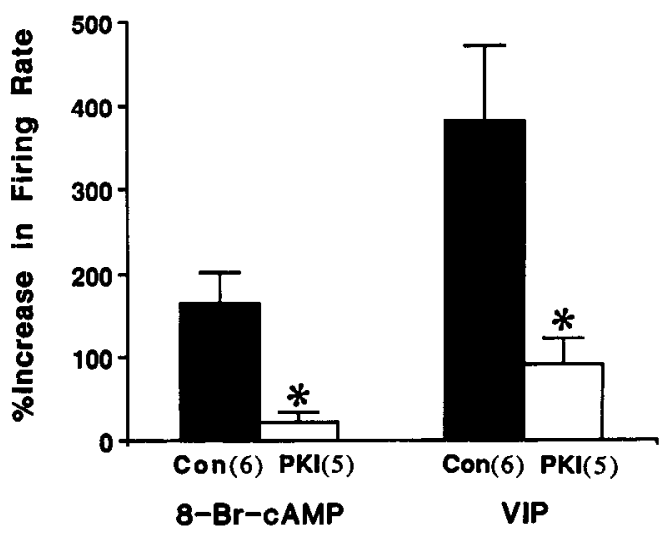

Figure 9. A, Summarized results showing the attenuation of the activation of VIP by $\mathrm{PKI}_{5-24}$ in LC cells. Control, electrodes containing 1 M KCl were used; $\mathrm{PKI}_{5-24}$, electrodes containing $\mathrm{PKI}_{5-24}(1-5 \mathrm{mg} / \mathrm{ml}$ in $1 \mathrm{M} \mathrm{KCl})$ were used. VIP $(400-500 \mu \mathrm{M}$ in ejection pipette) was tested twice in the same cells in each condition. $1^{\prime}$, the first application; $2^{\prime}$, the second application. *, significantly different from control, $p<0.02$. Because only 2 cells exhibited obvious oscillation in each of control or PKI $_{5-24}$ conditions, data were combined. $B$, The effects of 8 -Br-cAMP (1 mM) or VIP were examined in the same cells when electrodes containing PKI $(100-150 \mathrm{mg} / \mathrm{ml})$ were employed. PKI was ejected into cells prior to the appliction of $8-\mathrm{Br}-\mathrm{c} \Lambda \mathrm{MP}$ or VIP. Once the attenuation of 8-Br-cAMP was established, the effect of VIP was then examined. *, significantly different from controls (Con), $p<0.02$. The Arabic numerals in parentheses ( $A$ and $B$ ) represent number of cells tested.

1983). Therefore, the regulation or modulation of the activity of LC neurons would be anticipated to have widespread implications. With the ejection of PKI or $\mathrm{PKI}_{5-24}$ alone, most of cells showed a deceleration in firing or even a slight hyperpolarization. The ability of PKI or $\mathrm{PKI}_{5-24}$ by itself to inhibit LC neurons suggests that there is a partially active cAMP system under resting slice conditions in these cells. This observation is consistent with the previous suggestion that the spontaneous activity of LC cells might be modulated by endogenous cAMP (Wang and Aghajanian, 1987). The effect of VIP lasts much longer than that of other excitatory neurotransmitters previously tested on LC neurons, such as NMDA (Wang and Aghajanian, 1989a), carbachol (a muscrinic cholinergic agonist), and substance $\mathrm{P}$ (unpublished observations), raising the possibility that VIP, through an activation of cAMP, may play a special role in longterm regulation or modulation of the firing of LC neurons. VIP receptors have been found in many brain regions, and the basic electrophysiological actions of VIP have been studied in different brain regions (see Introduction in Wang and Aghajanian, 1989a). However, the ionic mechanism underlying the actions of VIP and the mediation of the electrophysiological actions of VIP by intracellular second messengers and/or protein phosphorylation have not been extensively studied. Therefore, it would be of interest to determine how the electrophysiological actions of VIP are mediated in other brain regions.

\section{References}

Adams WB, Levitan IB (1982) Intracellular injection of protein kinase inhibitor blocks the serotonin-induced increase in $\mathrm{K}^{+}$conductance in Aplysia neuron R15. Proc Natl Acad Sci USA 79:3877-3880.

Aghajanian GK, Rasmussen K (1989) Intracellular studies in the facial nucleus illustrating a simple new method for obtaining viable motoneurons in adult rat brain slices. Synapse 3:331-338.

Aghajanian GK, Wang Y-Y (1986) Pertussis toxin blocks the outward currents evoked by opiate and $\alpha_{2}$-agonists in locus coeruleus neurons. Brain Res 371:390-394.

Ashby CD, Walsh DA (1972) Characterization of the interaction of a protein inhibitor with adenosine $3^{\prime}, 5^{\prime}$-monophosphate-dependent protein kinases. I. Interaction with the catalytic subunit of the protein kinase. J Biol Chem 247:6637-6642.

Ashby CD, Walsh DA (1973) Characterization of the interaction of a protein inhibitor with adenosine $3^{\prime}, 5^{\prime}$-monophosphate-dependent protein kinases. II. Mechanism of action with the holoenzyme. J Biol Chem 248:1255-1261.

Borghi C, Nicosia S, Giachetti A, Said SI (1979) Vasoactive intestinal polypeptide (VIP) stimulates adenylate cyclase in selected areas of rat brain. Life Sci 24:65-70.

Castellucci VF, Nairn A, Greengard P, Schwartz JH, Kandel ER (1982) Inhibitor of adenosine $3^{\prime}: 5^{\prime}$-monophosphate-dependent protein kinase blocks presynaptic facilitation in Aplysia. J Neurosci 2:16731681.

Chen G-G, Chalazonitis A, Shen K-F, Crain SM (1988) Inhibitor of cyclic AMP-dependent protein kinase blocks opioid-induced prolongation of the action potential of mouse sensory ganglion neurons in dissociated cell cultures. Brain Res 462:372-377.

Cheng H-C, Kemp BE, Pearson RB, Smith AJ, Misconi L, Van Patten SM, Walsh DA (1986) A potent synthetic peptide inhibitor of the cAMP-dependent protein kinase. J Biol Chem 261:989-992.

Christie MJ, Williams JT, North RA (1989) Electrical coupling synchronizes subthreshold activity in locus coeruleus neurons in vitro from neonatal rats. J Neurosci 9:3584-3589.

Conn PJ, Strong JA, Azhderian EM, Nairn AC, Greengard P, Kaczmarek LK (1989) Protein kinase inhibitors selectively block phorbol ester- or forskolin-induced changes in excitability of Aplysia neurons. J Neurosci 9:473-479.

Daly JW, Padgett W, Seamon KB (1982) Activation of cyclic AMPgenerating systems in brain membranes and slices by the diterpene forskolin: augmentation of receptor-mediated responses. J Neurochem 38:532-544.

Deschodt-Lanckman M, Robberecht P, Christophe J (1977) Characterization of VIP-sensitive adenylate cyclase in guinea pig brain. FEBS Lett 83:76-80.

Drummond GI (1984) Cyclic nucleotides in the nervous system. New York: Raven.

Duman RS, Strada SJ, Enna SJ (1989) Glucocorticoid administration increases receptor-mediated and forskolin-stimulated cyclic AMP accumulation in rat brain cerebral cortical slices. Brain Res 477:166171.

Etgen AM, Browning ET (1983) Activators of cyclic adenosine $3^{\prime}: 5^{\prime}$ monophosphate accumulation in rat hippocampal slices: action of vasoactive intestinal peptide (VIP). J Neurosci 3:2487-2493.

Foote SL, Bloom FE, Aston-Jones G (1983) The nucleus locus coeruleus: new evidence of anatomical and physiological specificity. Physiol Rev 69:844-914. 
Levitan IB (1985) Phosphorylation of ion channels. J Membr Biol 87: $177-190$.

Madison DV, Nicoll RA (1986) Cyclic adenosine 3',5'-monophosphate mediates $\beta$-receptor actions of noradrenaline in rat hippocampal pyramidal cells. J Physiol (Lond) 372:245-259.

Magistretti PJ, Schorderet M (1985) Norepinephrine and histamine potentiate the increases in cyclic adenosine $3^{\prime}: 5^{\prime}$-monophosphate elicited by vasoactive intestinal polypeptide in mouse cerebral cortical slices: mediation by $\alpha_{1}$-adrenergic and $\mathrm{H}_{1}$-histaminergic receptors. $\mathrm{J}$ Neurosci 5:362-368.

Malhotra RK, Wakade TD, Wakade AR (1988) Vasoactive intestinal polypeptide and muscarine mobilize intracellular $\mathrm{Ca}^{2+}$ through breakdown of phosphoinositides to induce catecholamine secretion. J Biol Chem 263:2123-2126.

Mattera R, Graziano MP, Yatani A, Zhou Z, Graf R, Codina J, Birnbaumer L, Gilman AG, Brown AM (1989) Splice variants of the $\alpha$ subunit of the $G$ protein $G_{s}$ activate both adenylyl cyclase and calcium channels. Science 243:804-807.

Nestler EJ, Greengard P (1989) Protein phosphorylation and the regulation of neuronal function. In: Basic neurochemistry: molecular, cellular, and medical aspects, 4th Ed (Siegel GJ, Agranoff B, Albers RW, Molinoff P, eds), pp 373-398. New York: Kaven.

Nestler EJ, Tallman JF (1988) Chronic morphine treatment increases cyclic AMP-dependent protein kinase activity in the rat locus coeruleus. Mol Pharmacol 33:127-132.

Nicoll RA (1988) The coupling of neurotransmitter receptors to ion channels in the brain. Science 241:545-551.

Nygren LG, Olson L (1977) Intracisternal neurotoxins and monoamine neurons innervating the spinal cord: acute and chronic effects on cell and axon counts and nerve terminals densities. Histochemistry 52:281-306.

Olasmaa M, Påhlman S, Terenius L (1987) $\beta$-Adrenoceptor, vasoactive intestinal polypeptide (VIP) and neuropeptide tyrosine (NPY) receptors functionally coupled to adenylate cyclase in the human neuroblastoma SK-N-MC cell line. Neurosci Lett 83:161-166.

Onozuka M, Imai S, Deura S, Nishiyama K, Ozono S (1988) Stimulation of sodium current by cyclic AMP is mediated through protein phosphorylation in Euhadra neurons. Experientia 44:996-998.
Pfaffinger PJ, Martin JM, Hunter DD, Nathanson NM, Hillé B (1985) GTP-binding proteins couple cardiac muscarinic receptors to a $\mathrm{K}$ channel. Nature 317:536-538.

Quik M, Iversen LL, Bloom SR (1978) Effect of vasoactive intestinal peptide (VIP) and other peptides on CAMP accumulation in rat brain. Biochem Pharmacol 27:2209-2213.

Schubert B, VanDongen AMJ, Kirsch GE, Brown AM (1989) $\beta$-Adrenergic inhibition of cardiac sodium channels by dual G-protein pathways. Science 245:516-519.

Van Calker D, Muller M, Hamprecht B (1980) Regulation by secretin, vasoactive intestinal peptide, and somatostatin of cyclic AMP accumulation in cultured brain cells. Proc Natl Acad Sci USA 77:69076911.

Walsh DA, Ashby CD, Gonzalez C, Calkins D, Fischer EH, Krebs EG (1971) Purification and characterization of a protein inhibitor of adenosine 3',5'-monophosphate-dependent protein kinases. J Biol Chem 246:1977-1985.

Wang Y-Y, Aghajanian GK (1987) Excitation of locus coeruleus neurons by an adenosine $3^{\prime}, 5^{\prime}$-cyclic monophosphate-activatcd inward current: extracellular and intracellular studies in rat brain slices. Synapse 1:481-487.

Wang Y-Y, Aghajanian GK (1989a) Excitation of locus coeruleus neurons by vasoactive intestinal peptide: evidence for a G-proteinmediated inward current. Brain Res 500:107-118.

Wang Y-Y, Aghajanian GK (1989b) An inhibitor of cAMP-dependent protein kinase blocks the activation of rat locus coeruleus cell firing induced by 8-Br-cAMP, forskolin, and Ro20-1724. Soc Neurosci Abstr 15:1322.

Weiss S, Sebben M, Bockaert J (1985) Corticotropin-peptide regulation of intracellular cyclic AMP production in cortical neurons in primary culture. J Neurochem 45:869-874.

Williams JT, Marshall KC (1987) Membrane properties and adrenergic responses in locus coeruleus neurons of young rats. J Neurosci 7: 3687-3694.

Yatani A, Brown AM (1989) Rapid $\beta$-adrenergic modulation of cardiac calcium channel currents by a fast $G$ protein pathway. Science 245:71-74. 